\title{
Social Identity in a public hospital: sources, outcomes, and possible resolutions
}

\author{
Moran Shnapper-Cohen ${ }^{1} \cdot$ Niva Dolev $^{1} \cdot$ Yariv Itzkovich $^{1}$
}

Accepted: 14 January 2022

(c) The Author(s), under exclusive licence to Springer Science+Business Media, LLC, part of Springer Nature 2022

\begin{abstract}
The comprehensive, twofold goal of this paper is to investigate how social identities in a multilayered social platform of a public hospital are shaped, and to explain the impact of these identities on staff interrelations, patients, and the organization's overall ability to meet challenges. We conducted a qualitative study, collecting data from 30 employees working in a medium-sized public hospital in Israel using a semi-structured interview guide. Using a thematic analysis approach and drawing on social identity theory, we found that departmental identity is the most prominent social identity associated with the hospital staff. This identity was strengthened by strong in-group management, but little influenced by senior out-group management; its importance also caused organizational goals to be overlooked. We discuss these findings and offer recommendations for addressing the adverse impacts of departmental identity on staff, patients, and the organization's ability to meet challenges. This study has clarified sources and impacts of SI in a hospital context. It has also demonstrated the need for a more unified hospital identity to improve the hospital's daily work and achieve the organization's goals in a dynamic, competitive environment. Most literature on social identity has addressed personal- and group-level antecedents of social identity, neglecting the potential participation of in-group and out-group management in shaping these identities, as well as management's contribution to the achievement or nonachievement of organizational goals. By adopting a qualitative approach, the current study provides a deeper understanding of how senior management and direct in-group management can shape social identities - a perspective heretofore missing from the research. Recognizing these identity-shaping forces is essential for understanding the challenges that hospitals face, and the various (at times, life-or-death) consequences of these forces.
\end{abstract}

Keywords Social identity $\cdot$ intergroup relations $\cdot$ top management $\cdot$ qualitative method

\section{Introduction}

In recent decades, market dynamics, driven by digital advances and economic challenges, have compelled organizations to continuously strive to increase their ability to compete in volatile environments and establish their domination in the constant struggle for resources (Edmondson,

The corresponding author confirms that the study was approved by the Poriya ethics committee.

Moran Shnapper-Cohen moransc76@gmail.com

Niva Dolev

nivadolev@hotmail.com

Yariv Itzkovich

itzkovichyariv@gmail.com

1 Kinneret Academic College, on the Sea of Galilee, Israel
2012). Eager to promote patient-centricity under these conditions, healthcare organizations have implemented measures such as telemedicine and digitalization of patients' clinical histories, while concurrently struggling with lower budgets and ongoing social challenges, not least the COVID19 pandemic, that exhaust their resources (Prado-Prado et al., 2020). Healthcare institutions' efforts to add value for customers and staff and respond to these challenges have included promoting private sector management practices, such as lean management (Drotz \& Poksinska, 2014) and kaizen (Prado-Prado et al., 2020), which require cooperation between departments, professions, and, ultimately, individuals with diverse social identities (SIs).

In a hospital setting, staff members classify themselves and others within a range of corporate groups according to expectations and perceptions about professions (e.g., medicine versus nursing), diverse specialties (e.g., emergency medicine versus gastroenterology), and various statuses 
(e.g., junior versus senior doctors) that act and interact together (Hewett et al., 2015). In a public hospital context, where group memberships are hierarchical, firmly role-bound, and, simultaneously, departmental, intergroup dynamics are complex (Riskin et al., 2015).

Those managing members sustain this complexity in an effort to shape the SI of the group's social identity. Direct managers, who are considered to best represent the group identity, are expected to be deeply engaged in shaping the identities of their staff. In contrast, senior management representatives are unlikely to be perceived as in-group members and are thus expected to have less impact on group members' SIs (Dalton \& Chrobot-Mason, 2007; Hogg et al., 2012). Under such challenging conditions, the dynamics and sources of members' identities should be investigated, especially in healthcare, where interrelations between individuals and groups may prove to be a matter of life or death.

Consequently, understanding the various impacts of these SIs is paramount, due to their potential impact not only on patients but also on intergroup relations and, ultimately, the organization's ability to compete in a turbulent environment and achieve its goals.

The current paper has a comprehensive, two-fold aim: to investigate how diverse forces shape SI in a hospital through an exploration of some of its departments; and then to explain the impact of these identities on staff interrelations, patients, and the overall ability of the organization to meet its challenges.

To address these issues, the study embraces a wide perspective that integrates in-group ("us") and out-group ("them") antecedents of SI. This approach contributes to the existing literature that has focused on member- and grouplevel antecedents of SI. The current study, using a qualitative approach, provides a deeper understanding of the process through which social identities are shaped. This comprehensive view is novel, and has particular importance in the context of hospitals, where SI has an impact not only on individuals, but on their very lives (Steffens et al., 2021).

\section{Literature review}

\section{Social identity theory}

SI is defined as "part of an individual's self-concept which derives from his [sic] knowledge of his membership of a group (or groups) together with the value and the emotional significance attached to the membership" (Tajfel, 1978, p. 63). Once SI is shaped, it can explain individuals' feelings, thoughts, and behaviors as motivated by their group membership, as well as reflect the group's prototypical attributes (Hogg, 2001a, 2001b, 2005; Hogg et al., 2012).
Personal identity and its counterpart, SI, represent a twofold identity formation (Gallois et al., 2005) in which SI functions as a social glue binding individuals to their ingroup, enabling them to act on its behalf (Van Vugt \& Hart, 2004). When individuals are classified as group members, their other attributes are overlooked, and a greater emphasis is given to their commonalities with the group (Hogg et al., 2012).

Social identity theory (SIT) explains more than simply a broad view of the self. It provides insight into the nexus between the individual and the group that shapes the individual's perceptions of themselves and others in terms of social categories, and accounts for members' attitudes and behaviors as arising from a sense of belongingness (Turner et al., 1987).

SIT also offers a meaningful way to organize one's social world (Tajfel \& Turner, 1979; Turner et al., 1987) by classifying individuals in terms of a simplified dichotomy of in-group or out-group, within which individuals strive to maximize their positive distinctiveness. When SI is salient, people tend to focus more on shared attributes than on the distinctive personal properties that differentiate them from others within their group.

Accordingly, SIT has been used to explain both individuals' motivation to identify themselves as part of a group and their desire for distinctiveness (Hewstone et al., 2002; LaTendresse, 2000). Boosting their self-esteem is the underlying motivation of individuals concerning categorization, social identification, and social comparison, all of which are central processes involved in the formation of SI (Tajfel \& Turner, 1979). In this respect, SI stimulates group behavior through the two opposing mechanisms of discrimination and cooperation, which are used in congruence with the relevant context to maximize self-esteem (Kreindler et al., 2012).

Studies focusing on the positive contribution of SI have suggested that it enhances group cohesion and motivation (e.g., Ellemers et al., 2004), collaboration, altruistic behaviors, and positive group evaluations (Ashforth \& Mael, 1989). Studies addressing the benefits of SI for individuals have found that it increases job satisfaction, health, and wellbeing (Haslam et al., 2009a). Recent longitudinal research has highlighted the positive long-term impact of SI on individuals' health, well-being, and morale. Scholars have attributed these positive effects to the support and appreciation that groups provide-two mechanisms that protect group members from burnout during demanding periods (Haslam et al., 2009b).

Other studies have focused on the adverse effects of SI. In many circumstances, SI can increase in-group bias (e.g., McGarty, 2001) by stereotyping or discriminating against the out-group (Tajfel, 1978), thus fostering social competitiveness (Amiot \& Sansfaçon, 2011) and conflict. 


\section{Social identity in the healthcare context}

Professional identity includes both individuals' SI and the congruent desire to belong to a larger group with shared professional attributes (Ashforth et al., 2008). In healthcare, providers from various professions must collaborate to provide services to patients. For that purpose, individuals from diverse professional specialties and cultural backgrounds, who differ regarding the language, rules, and norms shaping their distinct professional identities, are grouped into multicultural professional teams (Watson et al., 2012).

Professional identity consists of a well-constructed set of attributes, values, motives, and experiences that define one's professional role (Warren \& Braithwaite, 2020). Professional subcultures, such as medicine, nursing, and administration, shape professional identities in hospital settings. These subcultures affect individuals' well-being, and their feelings, thoughts, and behaviors toward the organization (Callan et al., 2007).

Taking a broader perspective, Hewett et al. (2009) investigated the impact of the professional identity of physicians on the communication between diverse healthcare professions and on the quality of the resulting medical care given to patients. While the authors found that the medical specialty was the primary source of group identity, their findings, extending beyond the internal properties of identity also highlighted an external impact on patients. Specifically, they found that professional identities led to the creation of biased patient charts that reflected intergroup competition and that sought to enhance in-group identity. The study also confirmed that interprofessional competition can lead to overdiagnosis, thereby potentially threatening patients' lives. The authors argued that these dysfunctional communication patterns cannot be mitigated through interpersonal training, since they are rooted in group identities rather than in a lack of skills (Hewett et al., 2009).

Although previous studies have investigated the formation and impact of SI on individuals, groups, and external stakeholders (such as patients), relatively little attention has been paid to diverse in- and out-group antecedents of SI. Recently, Miles et al. (2021) showed that the content of feedback given by healthcare professionals depends on the social identity of participants in the process (i.e., the giver and the receiver) - an identity that is shaped, albeit not exclusively, by power differences. Although these findings are valuable, they have rarely been addressed in the SIT literature (Hogg, 2001a, 2001b, 2005).

\section{The present study}

This study's two aims are to investigate 1) how diverse in-group and out-group forces, shape members' social identities in a public hospital in Israel, and 2) to elucidate the impact of these identities. An exploratory qualitative inquiry is used to provide rich, in-depth perceptions of social identities expressed in the differentiation of feelings and behaviors.

\section{Method}

\section{Research design and sample}

We conducted a qualitative research study to comprehensively examine the social identity of staff in a hospital work environment. Qualitative research frameworks require researchers to study phenomena in their natural settings, understand and interpret the world-constructs of individual participants, attach considerable importance to personal knowledge, views, and perspectives, and note the meanings attributed by participants to personal experiences (Creswell, 1998; Patton, 1990; Sabar Ben-Yehoshua, 1999; Shkedi, 2004). Interviews provide descriptions and examples that can reveal the complexity, causes, and consequences of the phenomenon under study.

Between January and March 2017, semi-structured indepth interviews were conducted with 30 participants in a medium-sized general hospital in Israel. The hospital employs about 890 employees, including doctors, nursing and paramedical workers, and administration and maintenance workers. The staff include members of different religions and ethnic groups. The hospital is a peripheral hospital treating mostly to middle- and lower-class populations.

Consistent with previous guidelines (Bowen, 2008; Kerr et al., 2010), data saturation was reached after 30 interviews, at which point main themes related to the study (such as the dominant social identity, the perception of out-groups and issues related to contact) began to be repeated. A sample of this size has been acknowledged as more than adequate for qualitative research (Mason, 2010).

The interviewees were drawn from various departments and sectors in the hospital (medical, nursing, administration, and paramedical) to provide as broad a perspective as possible on the various levels of social identity. The interviewees were selected at random by the hospital administration, and the research team ensured that the sample reflected the sought-after diversity. Eleven medical departments, about half the administrative and paramedical departments, were represented in the sample. The respondents were managers and employees from different departments and ward levels, as shown in Table 1. Fifteen of the participants were women and 15 were men. Job tenure ranged from 6 months to 40 years table 2 . 
Table 1 Participants

\begin{tabular}{lll}
\hline Sector & Participants' function (profession) & Number \\
\hline Medical & Head of department (physician) & 6 \\
Nursing & Ward sister (nurse) & 5 \\
Administration & Head of household/admin & 3 \\
Nursing & Nurse in nursing administration & 3 \\
Medical & Physician in departments & 4 \\
Paramedical & Paramedical director & 3 \\
Administration & Household/admin worker & 4 \\
Medical & Physician in administration & 1 \\
Administration & Head of household/admin in administra- & 1 \\
& tion & \\
\hline
\end{tabular}

Table 2. Themes and sub-themes

\begin{tabular}{|c|c|}
\hline Theme & Sub-theme \\
\hline Social identity & $\begin{array}{l}\text { - The department as an ingroup } \\
\text { - Other departments as outgroup } \\
\text { - Hospital leadership as an outgroup }\end{array}$ \\
\hline $\begin{array}{l}\text { Sources of } \\
\text { departmen- } \\
\text { tal social } \\
\text { identity }\end{array}$ & $\begin{array}{l}\text { - Specialty status } \\
\text { - Perceived quality of the department } \\
\text { - Department leadership as drivers of social identity }\end{array}$ \\
\hline $\begin{array}{l}\text { Outcomes of } \\
\text { departmen- } \\
\text { tal social } \\
\text { identity }\end{array}$ & $\begin{array}{l}\text { Negative interpersonal relations between in and } \\
\text { outgroup } \\
\text { Stereotypes and biases } \\
\text { A sense of hostility between the departments } \\
\text { Competition and lack of cooperation } \\
\text { Difficulty to promote organizational goals } \\
\text { Impact on patients' care }\end{array}$ \\
\hline
\end{tabular}

\section{Data collection and interview design}

Common guidelines were applied for using the open-ended questions, which were structured and based on the literature review with the aim of exploring the roles that social identity and contact play in the hospital context. The interviews were flexible regarding the order of the questions, the time allocated for each question and the discussion of emerging topics. The interview guide included the following themes: strengths and weaknesses of the hospital and the department; feelings about the hospital and its image; the employee's main identities; the relationships within the department; and the contact and relationships between the departments. Each interview, conducted during working hours in a private room at the hospital, lasted approximately one hour. The interviews were conducted by all three researchers.

Permission to conduct the study was obtained from the hospital's vice-CEO, the chief doctor and department heads. All the participants signed informed consent forms, having been assured by the researchers that participation in the study was voluntary, that refusal to participate would have no effect on their careers, and that confidentiality and anonymity would be maintained throughout all stages of the study. All references to personal data were omitted from research records.

\section{Data analysis}

Data were analyzed using thematic analysis (Weber, 1990), encoding central themes and identifying patterns that emerged from them and that were related to the respondents' perceptions of social identity and its consequences. The data analysis process consisted of two stages. First, each researcher reviewed the interviews that she or he had conducted, performed lengthwise analyses, and encoded central themes. This stage is vital for preserving the context and content of the interviewees' statements. In the second stage, all the interviewers carried out transverse analyses to identify general patterns of themes and provide a comprehensive picture of perceptions and concepts. Inter-rater reliability was measured using Cohen's kappa and exceeded the threshold of $0.60(\kappa=0.63)$.

\section{Results}

The analysis of the interviews clarified the nature of social identity in the hospital, its sources, and its impact on the department, the staff, and the hospital as a whole. The findings are described using three main categories: social identity within the hospital, sources of departmental social identity, and outcomes of departmental social identity. A few main themes emerged within each category.

\section{Social identity within the hospital}

Several social identities emerged from the analysis: organizational (the hospital versus other hospitals), role (doctors, interns, nurses, maintenance), seniority (senior doctors, junior doctors, interns) and cultural groups. Participants spoke about "their" hospital, its uniqueness, advantages, and challenges compared to other hospitals. As one nurse put it, "The atmosphere, the family-like feeling, everyone is ready to help and contribute. It is a small hospital. In other hospitals you can get lost." Participants spoke about their role group and its unique attributes, role responsibilities, and challenges, as well as interrelations with other role groups, such as senior management mentors. They also mentioned the sometimes harsh approach toward interns, junior doctors, and nurses, the relations between senior and junior nurses, and the attitudes of different role holders to maintenance staff, such as cleaners.

To a lesser extent, participants spoke about cultural aspects of their identity. For example, they mentioned groups 
of employees speaking different languages (such as Arabic or Russian) within the hospital, which excludes other people from the conversation; or their own cultural identity, such as being an Arab Israeli or an immigrant who came to Israel at an older age. One physician told us that, "When I got to the hospital I was placed in the middle: Russian-speaking on one side and Arabic-speaking on the other. I didn't understand a thing. I think this is disrespect, to exclude people.” Personal cultural identity was discussed mainly in personal terms, and did not emerge as an issue within the hospital.

Departmental identity, however, was found to be an especially significant social identity factor, serving as the participants' main identity and outweighing any other group identity. A small number of subthemes emerged regarding departmental social identity: the department as an in-group, other hospital departments as out-groups, the hospital management as an out-group and the department as an in-group. Being the main social identity, the department emerged as the participants' main point of reference, and they tended to describe themselves in terms of their department and its specialty: "I am a nurse in the geriatric department ... I love working with this age group."

Identification with the department was expressed as high in-department solidarity. The participants often described the uniqueness, importance and quality of their department, conveying a sense of pride in it and promoting it inside and outside the hospital. For example, "I tell every pregnant woman to come to us at [name of hospital]. I know she will get excellent care in our department" (a neo-natal nurse); "I am proud to be part of this department, proud of the relationships between the staff" (a junior doctor); "We are very professional and family-like and there are great doctors here" (a nurse). Departmental identity was also expressed in terms of a desire for the department to flourish and an aspiration to develop and advance one's career within the department.

The department provided the majority of participants with a sense of belonging, which was very important to most of them. Belonging was expressed through discussion of a shared specialty, as well as the frequent use of the term "family-like" and descriptions of the close relationships within the department (both within and across roles). Different participants described daily life routines such as shared coffee breaks, celebrating holidays or sharing private events with their colleagues: "We celebrate holidays, and personal events, bring food to meetings and share it" (a paramedical staff member).

Social identity was also expressed in cooperation within the department, in ways that went beyond professional roles and transcended hierarchy and status boundaries. The participants described cooperation between department members with different roles in the form of mutual help, support, learning and teaching, and consulting. One doctor said, "There are excellent relationships between the physicians and the nurses; we include them in morning rounds ... We [the doctors] also give them [the nurses] lectures, share information." Another doctor added, "We respect each other. There is no ego ... we all know everything and everyone and do things together. The head nurses sit in on morning meetings, and there is a nurse on morning rounds." The nurses conveyed a similar view. For example, one nurse said, "There is an open relationship between us, we share, consult. Our head of department is something special, we can all express our opinions freely, he counts on us." This perceived cooperation was accompanied by a sense of support. A paramedical leader, for example, recounted, "We support each other. We help each other, we ask on WhatsApp: do you need help?" A member of the maintenance staff described receiving support from her department and its head when she was mistreated by another department (being left outside in the rain), and how they complained to management about the way she had been treated.

\section{Other departments as out-groups}

This in-group identification and solidarity was contrasted with other departments, which were perceived as the outgroup, thereby strengthening the in-group's social identity. References to the out-group were based on comparisons and expressed in a few subthemes: quality, professionalism and availability of resources.

Regarding quality, departments highlighted different ways in which they outperformed other departments, including the perceived importance of their specialty and its status, the quality of their staff and of the patient care they provide, their workload and hard work, and their values and relations. They tended to contrast their perceived strengths with the perceived weaknesses of other departments. For example, one doctor said, "We insist on professionalism, that everyone in the department knows all the patients, unlike other departments." Another doctor supported this view: "There is no ego in our department. However, you see ego in many departments."

At the same time, a department's identity was often defined by its perceived professionalism. This was expressed either as a sense of superiority over other departments and accompanied by a sense of entitlement based on the high perceived status of the specialty or department, or as a sense of inferiority in comparison to other (better or more prestigious) departments.

Such perceptions were accompanied by perceptions of the availability of resources compared to other departments, which served as social identity glue. While some participants reported a feeling of being invested in and being able to develop, others experienced relative deprivation. "There are many things we need but do not get. We have not received new employees for three years. Either there are no 
job vacancies available, or they go to other departments ... We talk about it among ourselves often" (physician, head of a department).

\section{Hospital leadership as an out-group}

As the main social identity was the department rather than the hospital as a whole, the hospital leadership was typically referred to as external to the department. Thus, the hospital leadership was perceived as an out-group, and this contributed to departmental social identity. In this respect, the department's social identity was formed and expressed by the mutual feelings of its members regarding their place and status in terms of the hospital's leadership's view and actions.

Participants from different departments and roles described hospital management as having power and influence regarding decisions and as a force responsible for resources, support, and attention external to the department. Discussion of senior management often centered on their view of and approach to the department: its perceived status and appreciation (or the lack thereof), the provision or withholding of resources, and preferences regarding decisions. Participants from various departments described competing for the management's support, both material and emotional, which was viewed as external to the department and its goals. The perceived differential management attitude was found to operate as a source supporting the departmental social identity and distancing it from other (out-group) departments. One department nurse, for example, expressed the view that "In general, hospital staff are being heard here, but in my department, we feel rejected. They [hospital management] give more to profitable departments. That is how our top management works ... " Another nurse from a different department added, "We feel that they do not remember us, that we are abandoned up here. They remember us only when they need us ... to sign off on someone's rehabilitation." Similarly, a physician from a third department said that, "Management is not attentive to my needs, for instance, regarding equipment. I sometimes get the impression that we do not get priority. For instance, the refrigerator of the patients' families ... a cooler ... Management never says to us, 'Tell us what you need, and we will fix it.",

\section{Sources of departmental social identity}

Beyond the social identity created by belonging to the same group and working together in close contact, the formation of the department as the main social identity was found to rely on a number of sources: the specialty and its general status, the status of the department within the hospital and outside it, and department leadership.

\section{Status of the specialty}

Closely related to their sense of belonging and pride as department members, participants also had a strong sense of their disciplinary and professional memberships. Specialization was the most salient professional identity for them, and its quality affected the department's prestige, both among themselves and in the views they attributed to the hospital leadership. Consistent with SIT, respondents made intergroup comparisons and categorized specialists from other departments as out-group members.

\section{Status of the department}

Throughout the interviews, and as mentioned earlier, there was a clear consensus among members of all departments that, in the words of a department nurse, "We have 'flagship' departments, some of the best in the country, that work admirably, while others do not." This view, regardless of whether it was expressed by more or less prestigious groups, contributed to the departments' social identities.

The reputation and evaluation of the quality of a department's work (both within the hospital and outside it) was not identical to the general status of the specialty, and was instead formed on the basis of the department's performance in the hospital and prestige beyond it. That performance, in turn, was related to the quality of the department's staff, the country and institution from which they obtained their degrees, the department's ability to attract staff and interns from high-status hospitals, staff retainment rates, availability of resources and access to technological advances, and future prospects in terms of development and resources. The criteria used by the participants to evaluate the quality of the department were its reputation within and outside the hospital and among management, the perceived quality of its doctors (including whether they had studied in Israel or, if not, in what country or institution) and whether they had previously worked in the center of the country, and the department's ability to attract interns.

\section{Department leaders as drivers of social identity}

Department heads were very often found to support and enhance the departmental sense of identity. As emerged from the interviews, they cultivated the departmental social identity by viewing their work from a narrow, departmental perspective, highlighting their uniqueness, expressing and sharing their disrespect (in strong departments) or their sense of envy and deprivation (in weaker departments) with their staff, and cultivating competition with other departments.

Highlighting such attempts to accentuate departmental uniqueness, a nurse working in nursing administration said, "Many heads of departments see their department as 
unique." A physician in the medical center's administration took the priority of the department over the medical center a step further: "Department heads are not always committed to the organizational spirit, but rather to their department. They are committed to their patients on the department level and not at the whole hospital." Department heads themselves supported this view: "As head of [X] department, I am less interested in what goes on in other departments. What interests me is that my department develops. I see other departments such as Cardiology and others, which are successful, and I want mine to develop too." Expanding this view to express disrespect toward other departments, a head of another department said, "What I do not like about my job is all that thing about working with other departments, because we are on a completely different level than they are, and it is hard to work with less professional staff."

The view that some departments are superior to others, as well as the perceived distribution of resources to more successful departments and the competition between departments over this, can help department heads to maintain their power through departmental social identity processes. In particular, participants spoke about the tendency of some department leaders to accept as little work as possible for their department, especially when this work comes from another department, with the aim of conserving the department's resources. As one physician said, "Some department leaders, when you turn to them asking for a patient admission, say: Why are you 'throwing' a patient at me? Their attitude is that we [from other departments] are bothering them ... and they project this attitude onto their teams."

\section{Outcomes of departmental social identity}

The focus on the department as the main social identity comes with a price tag for the organization. There are three main costs: negative intergroup relations between in- and out-groups, typified by hostility, competition, lack of cooperation and ego fights; difficulties in promoting organizational goals and driving organizational change and growth; and adverse impacts on patients.

\section{Negative interpersonal relations between groups}

The dominance of departmental social identities was found to create negative intergroup relations expressed in the form of lack of communication, hostility, competition, biases, and negative feelings and defiant behaviors toward other departments, all of which have a negative impact on the ability to cooperate and achieve mutual goals. As one physician explained, "This issue of communication between departments is of prime importance. As medical staff we have a calling, and if we will not work on our communication, we cannot succeed."

\section{Stereotypes and biases}

Stereotypes used to describe members of the out-group provided additional evidence of the superiority of the departmental identity over the professional one. In describing other departments, the homogeneity of the out-group was emphasized. Describing the biases between departments and their negative impacts, a nurse said, "Our relationships are not ideal. Everyone thinks that the other department does not do anything. If someone comes by and says, 'All you do here is drink coffee all day' it upsets me, and I want to be rude back."

\section{Hostility between departments}

Hostility was found to focus on perceived extra workload because of a lack of professionality or commitment from other departments, superior status in the eyes of hospital management or perceived superior resources, or the overall negative impact of a bad reputation: "Other departments are less professional and do things in a less professional way, or do not do a good enough job, and we have to deal with it and fix their mistakes" (a head of department); "It projects ... Someone says in a wedding to their relatives: 'I have been in $\mathrm{X}$ department in the hospital and they were terrible.' Everyone hears it and will then not want to come to the hospital, to any department" (a physician).

Those perceptions were found to create a negative climate in many cases, and they sometimes resulted in negative actions. As one nurse explained, "The office corridor, where there are many general nurses and nurses with other roles, accreditation, has been given the name "The Pure Souls Street.' They play dirty games, lots of ego wars" (a nurse in the administrative office).

\section{Competition and lack of cooperation}

Furthermore, the view some departments have of their own superiority was found to generate competition and make cooperation between departments difficult. This took the form of concealing information and competing for resources and credit. As one nurse described, "The nurses here in nursing administration are competitive. They do not give all the information or do not help, so that I am less successful."

Participants described conflicts between departments over resources (such as rooms, operating rooms, materials and time), which reflected either absolute low levels of resources or relative deprivation. Participants often felt that patients were admitted to their more crowded departments, or that they were given less operating room time or later operating hours. Fights for credit were described as the result: "For example, when we work on protocols, for which a few departments have to cooperate, there is friction over who 
will present the findings and will get the credit. There is a big identification with the department" (a departmental nurse).

\section{Difficulty in promoting organizational goals}

The hospital as a whole was described as investing considerable efforts in improvements and innovation in services, provision of better care for patients, and competition with other hospitals: "The hospital is developing, renewing itself. It develops new services such as MRI, blood vessel department, rheumatology. It is very impressive" (a physician).

However, the department identity, manifested through the mechanisms of a department's focus on narrow goals, competition, and lack of cooperation, was often found to distinguish between organizational and departmental goals, thereby having a negative impact on the hospital's performance and reputation: "We cannot go on like this. There is competition over patients among hospitals and we are losing in it. There needs to be a profound change in some departments, we do not perform complicated surgeries and there is chaos in the ER." (a department head). This process is exacerbated by department leaders who reject organizational changes in order to preserve their power. As a member of the paramedical staff explained, "Despite management efforts, some departments have a lot of power and reject the change, thus holding back the change and the hospital." Such objections related particularly to investment in other departments.

Another organizational goal, which was noted by some participants as hard to achieve within the current social identity, was to improve the organizational culture and leaders' attitudes toward staff and patients. This objective, too, was made difficult to achieve by department leaders being more concerned with maintaining their power within the department. As one physician said, "They [management] are trying to change department leaders' attitudes ... There is one department head in particular, who also projects his attitudes to the staff ... They even brought him a counselor. So far, it doesn't work very well. He keeps shouting, speaking disrespectfully, not cooperating."

\section{Impact on patient care}

These references to negative relations and the prioritization of department goals over organizational ones suggest a harmful impact on patient care. As the interviews showed, this impact can be attributed to a lack of information sharing regarding patients and a lack of resource sharing between departments (for example, admitting patients into less crowed departments, allocating operation rooms according to need rather than rigid adherence to departmental schedules, and improving the flow between the ER and other departments). As one paramedical staff remarked, "Do patients get the care they need and deserve here? I don't know. There are very good departments and departments where the level is not high, so overall I am not sure they do." A nurse added, "I would like to think that our lack of departmental cooperation does not negatively impact our care, but I am not sure about it anymore. I ask something from a doctor from a different department and he explains to me that what I am asking is not suitable and that he cannot do it ... Often I am convinced that it is just from not wanting to go the extra mile for another department." Regarding resources, a nurse explained, "If I find three packs of $[\mathrm{X}]$ and I cannot use them because I am not sure they belong to the department and therefore am hesitant to use them, and then I wait a long time for my order to get through, the patients are negatively affected."

Attributing this impact on patient care to a lack of cooperation, a head of physiotherapy expressed her frustration at not having multidisciplinary discussions about patients' needs: "If I was allowed to be present in their [other departments'] meetings and to explain to them what we are doing and what we can do, patients would receive much better care."

\section{Discussion}

Within the framework of SIT, this research investigated SI and intergroup relations in a hospital — a highly heterogeneous group context with many and diverse aspects of identity. The comprehensive goal was twofold. First, the study aimed to investigate how different in-group and out-group forces shape members' SI in a public hospital in Israel. The study therefore sought to clarify the infrastructure of SI in a hospital context, where identities can be created by a myriad of factors, including departmental, professional, organizational, ethnic, or seniority factors. Second, the study aimed to account for the impact of SI on staff interrelations, patients, and the organization's overall ability to meet the challenges facing it. Rich qualitative data, in the form of in-depth perceptions of SI expressed through feelings and behaviors, were gathered for these purposes.

Overall, the findings demonstrate that in-group and outgroup leadership factors shape SI and: (1) have an impact on the hospital's ability to achieve its goals; (2) shape conflicting intergroup relations; and (3) affect patient quality of care. These dynamics can be explained by the SIT of leadership.

\section{The social identity theory of leadership and organizational goals}

In his illuminating work focusing on leaders' misuse of power in the framework of SI, Hogg (2005) accounted for 
differences between in-group and out-group leadership and the many different contextual conditions in which in-group leaders can direct their social power and personal attributes to shape their group's SI and preserve their own power. This groundbreaking theory is based on the foundations of the SIT of leadership presented by Hogg a few years earlier (Hogg, 2001a; Hogg \& van Knippenberg, 2003). Extending the concept of SI to that of the SIT of leadership posits that the representation of groups is based on prototypes - that is, members who represent the essence of the group and its distinctiveness from other groups. Prototypical in-group members are a reliable source of in-group norms, and, as such, they can influence the identity and behavior of other group members. Leaders who are also in-group members are expected to hold prototypical characteristics of the group to a greater extent than do other group members or out-group leaders (Hogg et al., 2012; Steffens et al., 2021.). Therefore, such leaders are influential and trusted, which allows them to adjust the group's identity without being criticized. Hogg (2005) suggested that, under certain conditions, these leaders can apply the group's properties to emphasize their own prototypicality, preserve their power, and increase their and their group members' distinctiveness from other groups. Indeed, Rabbie and Bekkers (1978) found that insecure leaders are likely to provoke conflicts with other groups; this enables them to highlight differences between the groups and emphasize their own prototypicality and that of other in-group members, thereby ultimately increasing their own power (Hogg, 2005).

Although Hogg accounted for contextual threats to group SI, and thus group leadership, he overlooked the fact that in-group and out-group leadership jointly shape the group's SI; thus, in a delicate fabric of relations, out-group senior management leadership can serve as a contextual threat to in-group departmental leadership. In the healthcare sector, due to market dynamics, healthcare institutions promote private sector management practices, such as lean management (Drotz \& Poksinska, 2014) and kaizen (Prado-Prado et al., 2020), in response to organizational challenges. These trends threaten to reduce the power and centrality of in-group managers (Gandomani et al., 2020). As senior managers are viewed as out-group leaders, they are highly dependent on in-group leadership to implement these new practices. However, when under threat, internal leadership forces seek to enhance their group prototypicality and, ultimately, their own power.

The data presented in the current research support the concepts underlying the SIT of leadership by showing that departmental identity is strengthened by two distinct forces: departmental in-group leadership that promotes in-group/ out-group divisions, and senior management out-group leadership that differentiates among various departments regarding attitude and resource allocation.
This type of in-group leadership behavior has been welldocumented in the SIT of leadership, especially in Hogg's (2005) findings on the misuse of power. Hogg noted that prototypical in-group leaders provoke conflicts when under threat, emphasizing group prototypicality to enhance their own leadership power. The willingness of senior management to encourage patient-centricity requires a decentralization of leadership that is likely to reduce group leadership power (Drotz \& Poksinska, 2014; Prado-Prado et al., 2020). In the context considered in this study, this was evident in the willingness of department heads to protect their own power without considering the needs of the hospital or the impact on the SI of in-group members. By treating departments differently, senior management sustained these departmental identities.

\section{The social identity theory of leadership and intergroup relations}

All interviewees in the present study classified their SI on the basis of the department to which they belonged. Differential senior managerial attitudes contributed to the formation of that departmental SI, which was strengthened by the attitudes and behaviors of the department heads. As a result, members of highly valued departments sought to preserve their professional image and differentiate themselves from less-appreciated and less-valued departments, which affected their attitudes and behaviors toward these out-groups. This finding is consistent with those of previous studies, which have shown that preserving a high professional image leads to intergroup conflicts (Cuhadar \& Dayton, 2011; Rubin \& Hewstone, 2004). The perception of a department's professionalism constructs its appearance, which this study also found to predict discrete SIs. The SIT framework helps to elucidate the motivation of groups to distinguish themselves, making it clear that the differentiation is aimed at maintaining the department's professional image.

Furthermore, the high costs of medical care generate struggles over budgets and resources in hospitals. The present study shows that, under such challenging conditions, the support of hospital management is essential for departments and is a predictor of SI. SIT theorizes that when individuals identify with their group, their well-being is linked with the group's well-being (Van Vugt \& Hart, 2004), and the group's status is meaningful for the individuals' well-being. Senior management's selective attitudes toward various departments in our case created an experience of a particular hierarchy among departments, which was reflected in feelings of rejection, discrimination, or superiority among these departments and their members, which, in turn, shaped their SI. An insight provided by SIT in this context relates to the social structure of the groups as expressed in status 
and power differences between them. This is one element of social categorization (Kreindler et al., 2012).

Moreover, it seems that these drivers shape intergroup relations. A frustration-aggression effect was identified in the departments, which felt that other departments impeded their professionalism, creating further conflict. Although there was increased positive contact within departments (both within and across professional roles and statuses), which manifested through solidarity and an in-group bond, the opportunities for interdepartmental connection were found to be minimal and artificial, and, in most cases, involved conflicts. While these conflicts could be actual or relative, on the whole, they sustained the departmental SI, prevented cooperation between groups, and evoked mutual negative behaviors and feelings. The present findings also indicate a lack of shared goals, consistent with previous studies suggesting that a lack of shared goals has a negative impact on the quality of relationships (Lloyd et al., 2011).

\section{The social identity theory of leadership and patients}

Thomson et al. (2015) found that in the healthcare context specifically, focusing on the goals of one specific sector instead of the goals of the patient or the team affects the quality of communication between teams and their overall ability to provide optimal patient care. The present study's findings are consistent with previous findings that SI can have a negative impact on patients and should therefore be managed carefully.

Out-group threats to departmental prestige and leadership strength followed by in-group leadership efforts to maintain power can be predicted and have been well-documented. Nevertheless, selective treatment by senior leadership exacerbates conflicts and prejudice between departments, making organizational goals even more difficult to achieve. Such findings are all the more significant given the ethnic gap between employees across departments, which can contribute to SI (Klein et al., 2019), but remains inferior to the forces mentioned above.

In light of these findings and the presence of prejudice between departments, contact theory and contact strategies should be used to remedy negative intergroup interpersonal relationships, enhance patient care, and promote organizational goals.

\section{Practical implications to resolve these challenges}

1) Considering these findings, shared goals, such as mutual responsibility for patient care, should be identified, prioritized, and implemented.

2) Senior management should maintain equality between departments, and lower-status departments should be given support (in terms of capacity-building measures).
Based on the understanding that all departments are vital for the hospital, a shared identity can be promoted.

3) To promote positive intergroup relations, interdepartmental cooperation should be embedded in daily practice, encouraged, and rewarded by human resources practices centering on staff exchange projects that, in turn, can enhance positive intergroup relations. In this respect, senior leadership can support these efforts by avoiding cultivating separate identities through selective treatment of departments.

These steps are well-grounded in contact theory (Allport, 1954; Dovidio et al., 2011; Visintin et al., 2017), which stresses the need for equal group status (that is, contact between those sharing a similar status); commonly shared goals with an active, goal-oriented effort; intergroup cooperation without intergroup competition; and the support of authorities (Pettigrew, 1998; Pettigrew et al., 2011) in these processes of forming a more united identity between individuals at the hospital, rather than separate departmental identities that are costly to hospitals and patients alike.

\section{Contribution}

The results of this study contribute to the literature in several ways. Although previous research has examined SI in hospitals (Penman, 2015; Thomson et al., 2015) and among specializations in the medical sector (Hewett et al., 2009), to the best of our knowledge, the departmental SI that emerges from examining all sectors-medical, nursing, administrative, and paramedical—has not been investigated until now.

Another contribution of this study is its extension of SIT to leadership. In contrast to previous studies, which have focused on the internal factors and implications of SI, we analyzed various external causes and outcomes of SI. The literature has detailed the intergroup factors that create SIs, such as group characteristics and the motivation to belong (Amiot \& Sansfaçon, 2011; Brown, 2000; Callan et al., 2007). It has also noted the in-group consequences, such as effects on the individual's sense of self-worth within the group and on the cohesion of the group (Brown, 2000). The present study provides insights into the effect of out-group elements on SI formation in an organizational context, including in-group and out-group interrelations and selective attitudes of management.

\section{Limitations}

A limitation of this study is that it was conducted in one hospital; that is, in a single organization. Although this approach can help to preserve data homogeneity and ensure 
control of various contextual variables, it raises the question of whether the findings were attributable to the organizational culture of this specific hospital or to some unique elements of its intersectoral relationships. Future research should investigate other medical organizations, such as schools and universities, to enrich the data and improve the generalizability of the findings.

\section{Conclusion}

This study has clarified sources and impacts of SI in a hospital context. It has also demonstrated the need for a more unified hospital identity to improve the hospital's daily work and achieve the organization's goals in a dynamic, competitive environment. We believe that this study offers a more comprehensive perspective on the in- and out-group leadership antecedents of SI and their impacts on organizational ability to achieve goals, promote intergroup relations, and enhance the quality of patient care.

Future studies can examine ways of instilling organizational SI in employees to enhance their identification with the organization and bridge departmental SIs. Rovio-Johansson and Liff's (2012) showed how to achieve greater cooperation in a multiprofessional team through verbal abilities; similar investigation of organizational communication mechanisms in the context of SI could significantly contribute to the understanding and bridging of departmental identities if used effectively by senior management figures who currently use their leadership power to fuel departmental identity. In summary, the current study offers an SI perspective on the interrelations between individuals, groups, and the organization as a whole.

Supplementary Information The online version contains supplementary material available at https://doi.org/10.1007/s12144-022-02729-4.

\section{Declaration}

The corresponding author states that there is no conflict of interest The corresponding author confirms that the study was approved by the institute's ethics committee (the name is added to the title page for blind review purposes).

The corresponding author confirms that datasets generated and/or analyzed during the current study are available from the corresponding author on reasonable request.

Informed consent was obtained from all individual participants included in the study.

The datasets generated during and/or analyzed during the current study are available from the corresponding author on reasonable request.

\section{References}

Allport, G. W. (1954). The Nature of Prejudice. Addison-Wesley. Amiot, C. E., \& Sansfaçon, S. (2011). Motivations to identify with social groups: A look at their positive and negative consequences.
Group Dynamics: Theory, Research, and Practices, 15(2), 105-127.

Ashforth, B. E., \& Mael, F. (1989). Social identity theory and the organization. Academy of Management Review, 14(1), 20-39.

Ashforth, B. E., Harrison, S. H., \& Corley, K. G. (2008). Identification in organizations: An Examination of Four Fundamental Questions. Journal of Management, 34(3), 325-374.

Bowen, G. A. (2008). Naturalistic inquiry and saturation concept: A research note. Qualitative Research, 8(1), 137-152.

Brown, R. (2000). Social identity theory: Past achievements, current problems and future challenges, (30) 6, 745-778.

Callan, V. J., Gallois, C., Mayhew, M. G., Grice, T. A., Tluchowska, M., \& Boyce, R. (2007). Restructuring the multi-professional organization: Professional identity and adjustment to change in a public hospital. Journal of Health and Human Services Administration, 29(4), 448-477.

Creswell, J. W. (1998). Qualitative inquiry and research design: Choosing among five traditions. Sage Publications.

Cuhadar, E., \& Dayton, B. (2011). The social psychology of identity and intergroup conflict: From theory to practice. International Studies Perspectives, 12(3), 273-293.

Dalton, M., \& Chrobot-Mason, D. (2007). A theoretical exploration of manager and employee social identity, cultural values and identity conflict management. International Journal of Cross Cultural Management, 70(2), 169-183.

Dovidio, J. F., Eller, A., \& Hewstone, M. (2011). Improving intergroup relations through direct, extended and other forms of indirect contact. Group Processes \& Intergroup Relations, 14(2), 147-160.

Drotz, E., \& Poksinska, B. (2014). Lean in healthcare from employees' perspectives. Journal of Health Organization and Management, 28(2), 177-195.

Edmondson, A. C. (2012). Teaming: How organizations learn, innovate, and compete in the knowledge economy. John Wiley \& Sons.

Ellemers, N., De Gilder, D., \& Haslam, S. (2004). Motivating individuals and groups at Work: A social identity perspective on leadership and group performance. The Academy of Management Review, 29(3), 459-478.

Gallois, C., McKay, S., \& Pittam, J. (2005). Intergroup communication and identity: Intercultural, organizational, and health communication. In K. L. Fitch \& R. E. Sanders (Eds.), Handbook of Language and Social Interaction (pp. 231-250). Lawrence Erlbaum.

Gandomani, T. J., Tavakoli, Z., Zulzalil, H., \& Farsani, H. K. (2020). The role of project manager in agile software teams: A systematic literature review. IEEE Access, 8, 117109-117121.

Haslam, S. A., Jetten, J., \& Waghorn, C. (2009b). Social identification, stress, and citizenship in teams: A five-phase longitudinal study. Stress Health, 25(1), 21-30.

Haslam, S. A., Jetten, J., Postmes, T., \& Haslam, C. (2009a). Social identity, health and well-being: An emerging agenda for applied psychology. Applied Psychology: International Review, 58(1), $1-23$.

Hewett, D.G., Watson, B.M., Gallois, C., Ward, M., \& Leggett, B.A. (2009). Intergroup communication between hospital doctors: Implications for quality of patient care. Social Science and Medicine, (69) 12, 1732-1740.

Hewett, D., Watson, B., \& Gallois, C. (2015). Communication between hospital doctors: Underaccommodation and interpretability. Language and Communication, 41(1), 71-83.

Hewstone, M., Rubin, M., \& Willis, H. (2002). Intergroup bias. Annual Review of Psychology, 53, 575-604.

Hogg, M. A. (2001a). Social identification, group prototypicality, and emergent leadership. In M. A. Hogg \& D. J. Terry (Eds.), Social Identity Processes in Organisational Contexts (pp. 197-212). Psychology Press.

Hogg, M. A. (2001b). From prototypicality to power: A social identity analysis of leadership. In S. R. Thye, E. J. Lawler, M. W. Macy, 
\& H. A. Walker (Eds.), Advances in Group Processes (pp. 1-30). Elsevier.

Hogg, M. A. (2005). Social identity and misuse of power: The dark side of leadership. Brooklyn Law Review, 70, 1239-1257.

Hogg, M. A., \& van Knippenberg, D. (2003). Social identity and leadership processes in groups. In M. P. Zanna (Ed.), Advances in Experimental Social Psychology (pp. 1-52). Academic Press.

Hogg, M. A., van Knippenberg, D., \& Rast III, D. E. (2012). The social identity theory of leadership: Theoretical origins, research findings, and conceptual developments. European Review of Social Psychology, 23(1), 258-304.

Kerr, C., Nixon, A., \& Wild, D. (2010). Assessing and demonstrating data saturation in qualitative inquiry supporting patient-reported outcomes research. Expert Review of Pharmacoeconomics and Outcomes Research, 10(3), 269-281.

Klein, G., Shtudiner, Z., Kantor, J., Mollov, B., \& Lavie, C. (2019). Contact theory in the workplace: The case of Jewish-Arab contact in Israel. Journal of Community \& Applied Social Psychology, 29(2), 146-164.

Kreindler, S. A., Dowd, D. A., Star, H. D., \& Gottschalk, T. (2012). Silos and social identity: The social identity approach as a framework for understanding and overcoming divisions in health care. The Milbank Quarterly, 90(2), 347-374.

LaTendresse, D. (2000). Social identity and intergroup relations within the hospital. Journal of Social Distress and the Homeless, 9(1), 51-69.

Lloyd, J. V., Schneider, J., Scales, K., Bailey, S., \& Jones, R. (2011). Ingroup identity as an obstacle to effective multi-professional and interprofessional teamwork: Findings from an ethnographic study of healthcare assistants in dementia care. Journal of Interprofessional Care, 25(5), 345-351.

Mason, M. (2010). Sample size and saturation in $\mathrm{PhD}$ studies using qualitative interviews. Forum: Qualitative. Social Research, 11) 3,8

McGarty, C. (2001). Commentary: Social identity theory does not maintain that identification produces bias, and self-categorization theory does not maintain that salience is identification: Two comments on Mummendey, Klink and Brown. The British Journal of Social Psychology, 40, 173-176.

Miles, A., Ginsburg, S., Sibbald, M., Tavares, W., Watling, C., \& Stroud, L. (2021). Feedback from health professionals in postgraduate medical education: Influence of interprofessional relationship, identity and power. Medical Education, 55(4), 518-529.

Patton, M.Q. (1990). Qualitative Evaluation and Research Methods (2nd ed.). Sage Publications, Inc.

Penman, E. S. (2015). Communication accommodation between healthcare providers at a private hospital in England: How does identity talk? Master's thesis. University of Jyväskylä.

Pettigrew, T. F. (1998). Intergroup contact theory. Annual Review of Psychology, 49(1), 65-85.

Pettigrew, T. F. (2008). Future directions for intergroup contact theory and research. International Journal of Intercultural Relations, 32(3), 187-199.

Pettigrew, T. F., \& Tropp, L. R. (2008). How does intergroup contact reduce prejudice? Meta-analytic tests of three mediators. European Journal of Social Psychology, 38(6), 922-934.

Pettigrew, T. F., Tropp, L. R., Wagner, U., \& Christ, O. (2011). Recent advances in intergroup contact theory. International Journal of Intercultural Relations, 35(3), 271-280.

Prado-Prado, J.C., García-Arca, J., Fernández-González, A.J., \& Mosteiro-Añón, M. (2020). Increasing competitiveness through the implementation of lean management in healthcare. International Journal of Environmental Research and Public Health, (17) $14,4981$.

Rabbie, J. M., \& Bekkers, F. (1978). Threatened leadership and intergroup competition. European Journal of Social Psychology, 8(1), 9-20.

Riskin, A., Erez, A., Foulk, T. A., Kugelman, A., Gover, A., Shoris, I., Riskin, K. S., \& Bamberger, P. A. (2015). The impact of rudeness on medical team performance: A randomized trial. Pediatrics, $136(3), 487-495$.

Rovio-Johansson, A., \& Liff, R. (2012). Members' sensemaking in a multi-professional team. Journal of Health Organization \& Management, 26(5), 605-620.

Rubin, M., \& Hewstone, M. (2004). Social identity, system justification, and social dominance: Commentary on Reicher, Jost et al., and Sidanius et al.. Political Psychology, (25) 6, 823-844.

Sabar Ben-Yehoshua, N. (1999). Qualitative research in teaching and learning (5th edition). Modan.

Shkedi, A. (2004). Words of meaning: Qualitative research - theory and practice. Ramot Publishers.

Steffens, N. K., Munt, K. A., van Knippenberg, D., Platow, M. J., \& Haslam, S. A. (2021). Advancing the social identity theory of leadership: A meta-analytic review of leader group prototypicality. Organizational Psychology Review, 11(1), 35-72.

Tajfel, H. (1978). Differentiation between social groups: Studies in the social psychology of intergroup relations. Academic Press.

Tajfel, H., \& Turner, J.C. (1979). An integrative theory of intergroup conflict. In Austin, W.G., \& Worchel, S. (Eds.). The Social Psychology of Intergroup Relations (pp. 33-37). Brooks/Cole.

Tajfel, H., \& Turner, J. C. (1986). The social identity theory of intergroup behavior. In S. Worchel \& W. G. Austin (Eds.), Psychology of Intergroup Relations (pp. 7-24). Nelson-Hall.

Thomson, K., Outram, S., Gilligan, C., \& Levett-Jones, T. (2015). Interprofessional experiences of recent healthcare graduates: A social psychology perspective on the barriers to effective communication, teamwork, and patient-centred care. Journal of Interprofessional Care, 29(6), 634-640.

Turner, J.C., Hogg, M.A., Oakes, P.J., Reicher, S.D., \& Wetherell, M.S. (1987). Rediscovering the social group: A self-categorization theory. Basil Blackwell.

Van Vugt, M., \& Hart, C. M. (2004). Social identity as social glue: The origins of group loyalty. Journal of Personality and Social Psychology, 86(4), 585-598.

Visintin, E. P., Voci, A., Pagotto, L., \& Hewstone, M. (2017). Direct, extended, and mass-mediated contact with immigrants in Italy: Their associations with emotions, prejudice, and humanity perceptions. Journal of Applied Social Psychology, 47(4), 175-194.

Warren, M., \& Braithwaite, C. (2020). Understanding the relationship between professional regulation and professional identity in health care. Journal of Medical Regulation, 106(2), 7-14.

Watson, B. M., Hewett, D. G., \& Gallois, C. (2012). Intergroup communication and healthcare. In H. Giles (Ed.), The Handbook of Intergroup Communication (pp. 293-305). Routledge.

Weber, R.P. (1990). Basic content analysis ( $2^{\text {nd }}$ Ed.). Sage.

Publisher's note Springer Nature remains neutral with regard to jurisdictional claims in published maps and institutional affiliations. 